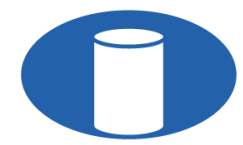

IBRACON Structures and Materials Journal

Revista IBRACON de Estruturas e Materiais

IBRACON

ISSN 1983-4195

ismj.org

ORIGINAL ARTICLE

\title{
Parametric analysis of analytical solutions of the rollover of precast beams on bearing pads
}

\section{Análise paramétrica da instabilidade por tombamento de vigas pré-moldadas sobre almofadas de apoio}

\author{
Marina Fernandes Alvarenga Oliveira ${ }^{a}$ \\ Pablo Augusto Krahl ${ }^{\mathrm{b}}$ \\ Maria Cristina Vidigal de Lima ${ }^{\mathrm{a}}$
}

${ }^{a}$ Universidade Federal de Uberlândia - UFU, Faculdade de Engenharia Civil, Uberlândia, MG, Brasil

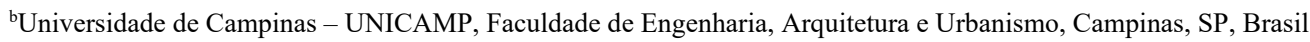

Received 04 July 2019

Accepted 26 Febuary 2020

\begin{abstract}
Due to low stiffness to lateral bending, long prestressed precast concrete beams are subject to lateral instability. For this reason, the safety analysis of these beams during the transitory stages of transport, lifting and assembly is fundamental. This work presents a nonlinear analytical model for the parametrical analysis of beams on bearing pads in their definitive location, without the effective connections being made. Such a solution determines a critical load of instability and considers the geometry of the cross-section, physical characteristics of the materials as well as geometric imperfections. A parametrical simulation is performed for the initial eccentricity, the initial rotation of the beam, concrete resistance, bearing pads dimensions, and the cross-section of the beam. The results show that the parameters of most considerable influence on beam stability are rotation stiffness of the bearing and the geometric characteristics of the cross-section of the beam, which can result in a reduction of about $50 \%$ of the critical rollover load. In addition, the cracking load may, in some cases, be close to the critical toppling load.
\end{abstract}

Keywords: stability, precast beams, analytical study, parametric study, Monte Carlo simulation.

Resumo: Devido à baixa rigidez à flexão lateral, vigas pré-moldadas protendidas de concreto longas e esbeltas estão sujeitas aos riscos de instabilidade lateral. Nestes termos, é fundamental analisar a segurança dessas vigas durante as fases transitórias de transporte, içamento e montagem. Este trabalho apresenta um modelo analítico não linear para análise paramétrica de vigas já posicionadas em seu local definitivo sobre almofadas de apoio, quando as ligações ainda não foram efetivadas. A força crítica de instabilidade lateral foi calculada considerando a geometria da seção transversal, as características físicas dos materiais, bem como imperfeições geométricas. Uma simulação paramétrica foi feita para a influência da excentricidade lateral inicial da viga, a rotação inicial do apoio, a resistência à compressão do concreto, as dimensões do aparelho de apoio e a seção transversal da viga. Os resultados mostram que os parâmetros de maior influência na estabilidade da viga foi a rigidez a rotação do apoio e as características geométricas da seção transversal da viga, podendo resultar em redução da ordem de $50 \%$ da força crítica de tombamento. Além disso, a força de início da fissuração, em alguns casos, pode estar bem próxima a força crítica de tombamento.

Palavras-chave: estabilidade, vigas pré-moldadas, estudo analítico, estudo paramétrico, simulação de Monte Carlo.

How to cite: M. F. A. Oliveira, P. A. Krahl, and M. C. V. Lima, "Parametric analysis of analytical solutions of the rollover of precast beams on bearing pads," Rev. IBRACON Estrut. Mater., vol. 13, no. 5, e13511, 2020, https://doi.org/10.1590/S1983-41952020000500011

Corresponding author: Marina Fernandes Alvarenga Oliveira. E-mail: marinaalvarenga.engcivil@gmail.com

Financial support: The authors would like to thank FAPEMIG (Public Call 01/2015-APQ00099-15) for the financial support.

Conflict of interest: Nothing to declare. 


\section{INTRODUCTION}

Precast and prestressed concrete beams are elements widely used in the most diverse types of construction systems. Such elements are found with increasing spans, slender cross-sections, and improved mechanical efficiency, due to the advance of technology associated with concretes that are more resistant, along with more precise and efficient manufacturing processes.

During the assembly process of a precast structure, it is common that its elements are maintained in temporary situations until the end of production. In the case of beams for bridges and viaducts, this occurs during the transportation, hoisting, and even after being placed in their permanent position, when there is still no slab or other structural bracing element necessary for guaranteeing the complete stability of such structures. In these stages, the beam is usually bisupported, without restriction across all movements, and as such subject to actions that can interfere in its stability, which means there exists a high probability of rollover with rigid body rotation, accompanied by deformation and critical stresses.

Rollover of precast beams is a case of collapse due to lateral instability, where support devices produce little restriction to the rotation of the beam to its longitudinal axis. In this type of failure, there typically occurs a combination between lateral flexion, rigid body rotation (around the longitudinal axis) and twisting. The twisted portion usually is much less than the rigid body portion [1] and [2], which can thus be dismissed. There are those factors that directly influence the lateral stability of precast beams, such as the length of the beam, the geometry of the cross-section, in addition to lateral forces, as in the case of wind.

Several accidents caused by lateral instability of precast beams justifies the study on which this paper is based. In June of 2000, the Souvenir Boulevard Bridge, under construction in the city of Laval in Canada, suffered the partial collapse of various precast beams with a span of approximately $33.5 \mathrm{~m}$. The cause of the accident was the inadequate conditions of the supports that produced a state of unstable equilibrium on the beams [3]. In 2007, nine out of the eleven precast beams collapsed that were part of the Red Mountain Freeway in Arizona, United States (Figure 1). Lateral instability caused one beam to collapse, triggering the fall of the eight remaining beams through a domino effect. The rollover of this beam was caused by a critical combination of many factors, such as geometric imperfections of the beam, bad positioning on the support, the presence of wind, and a lack of lateral bracing [4]. The study by Bairán and Cladera [5] analyzed the partial collapse of a structure covering a sports gymnasium, which was caused by the rollover of precast beams. According to these authors, the accident was due, possibly, to the inadequate positioning of the support device, as the position in which it was placed did not present sufficient stiffness to the lateral rotation, so that it guarantees the stability of the beam.
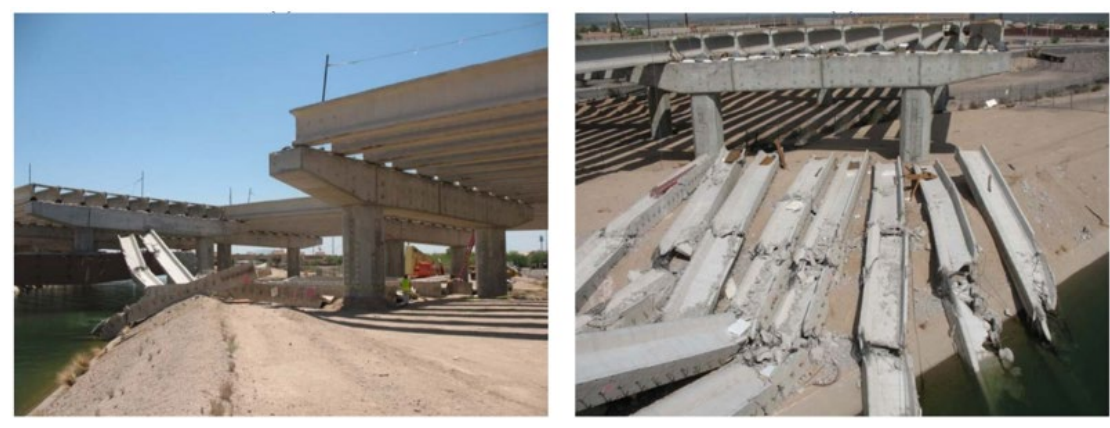

Figure 1. Beam collapse in Arizona (EUA). Source: Oesterle et al. [4]

Some analytical studies were performed to present solutions that verify the safety of precast beams on support devices. The study by Mast [1] proposed an equation, through the static equilibrium of moments for determining the safety factor of the beam in a transitory stage, while considering stiffness, rotation and superelevation of the support, the physical properties of the beam and the initial lateral eccentricity. The equation proposed by Mast [1] is considered in a normative sense by the PCI (Precast/Prestressed Concrete Institute), to evaluate the critical rollover load of a beam. Other authors also developed equations to determine the critical self-weight of the beam when supported by support devices, for example in Burgoyne and Stratford [6], Plaut and Moen [7], Lee et al. [8] and Lee [9], in addition to Krahl et al. [10]. Burgoyne and Stratford [6] did not consider the superelevation of the support, neither the initial eccentricity in their equation. Through their research, Plaut and Moen [7] developed an equation that considered a 
curved beam under the action of its self-weight and wind. In Lee et al. [8], the proposal was put forward of an equation that also considered the influence of wind, but without initial eccentricity. Lee et al. [8] proposed an equation for a straight beam, under the influence of self-weight, but considered the effect of beam twisting. Krahl et al. [10], through the Rayleigh-Ritz method, proposed an equation for defining the critical load concentrated in the middle of the span, causing lateral instability of the beam, besides the definition of the critical load distributed uniformly, i.e., critical selfweight.

Hurff and Kahn [11] performed experimental analyzes on a beam of a $30.5 \mathrm{~m}$ length and cross-section of the BT54 type, on an elastomeric bearing pad that was reinforced with four steel plates. To perform the test, a concentrated vertical load with a gravitational force simulator was employed, which does not offer resistance to lateral deformations or twisting. The authors concluded that the rigid body rotation to was more significant than rotation due to elastic deformations, and that the initial imperfections of the beam and rotation on the support are substantial when dealing with lateral stability.

This paper has as its objective to study the problem of lateral stability of beams during assembly of the structure onto elastomeric supports, usually in a bi-support arrangement, through an analytical approach. The elastomeric pad support device was chosen as the object of analysis, as it is widely used support in the construction of bridges and viaducts using precast beams. A schematic representation of the beam indicating the initial eccentricity and support rotation parameters are presented in Figure 2.

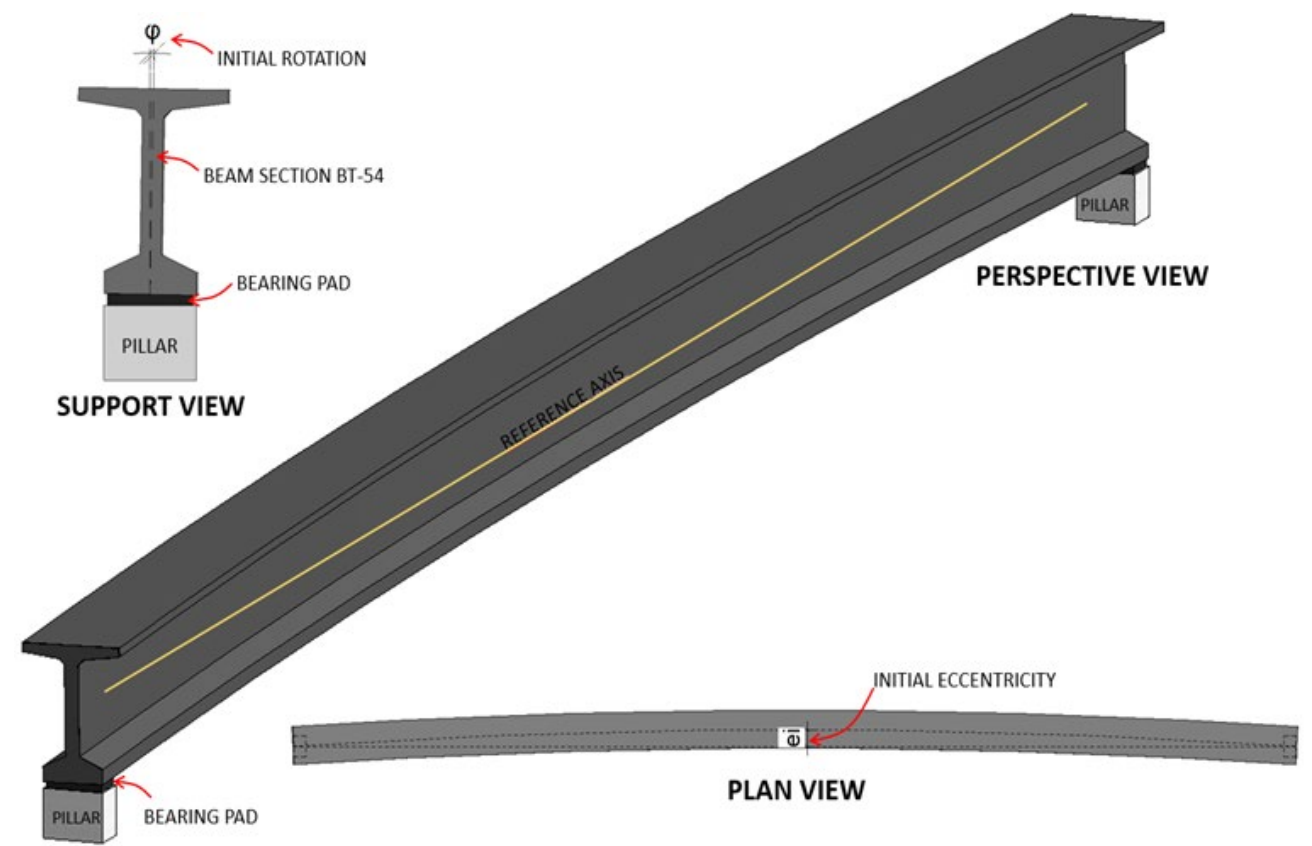

Figure 2. Scheme for the analyzed beam. Source: Authors.

The objective of the study was to propose an analytical solution to determine the rollover load with the rigid body rotation of the beam, due to conditions of imperfections of the beam, such as eccentricity and initial rotation, while analyzing the critical stress for initiating cracking of the beam due to additional stress of traction generated during tipping, as well as check for the influence of initial lateral eccentricity, the characteristics of the concrete, the crosssection of the beam and the rigidity of the pad in parametric analytical simulations.

The equations presented in this study for determining the critical rollover load of precast beams were developed with the use of the Rayleigh-Ritz method, which is based on the principle of stationary potential energy.

In order to evaluate the initial cracking of the beam, the calculation was presented for the maximum traction stress of the beam during the rollover, i.e., under the nonlinear geometric regime. Initial cracking was considered in this study, as the moment when traction stress on the beam is higher than the resistance to concrete traction.

Finally, a parametric analysis was developed based on the Monte Carlo simulation to verify the behavior of analytical solutions for the critical loads obtained. As a basis for the analysis, data were used from the beam tested by 
Hurff and Kahn [11]. The analysis parameters were: initial lateral eccentricity, initial rotation on the support, the compressive strength of the concrete, dimension of the support device and the cross-section of the beam.

\section{EQUATION FOR LATERAL INSTABILITY DUE TO ROLLOVER}

The problem with the study of balance in nonlinear analysis of precast beams supported on support devices was developed in this paper employing the Rayleigh-Ritz method. This method is based on the principle of stationary potential energy and applies to linear as well as nonlinear structures, which are statistically determined. Therefore, it is possible to obtain the closed-form nonlinear analytic solution to structural problems. For such, one should determine an appropriate function that represents the geometric configuration of the structure concerning instability, through a linear combination of degrees of freedom $\alpha_{\mathrm{i}}$. This function was used in the total energy equation $\Pi$, which consists of the sum of the internal energy $U$ and the work carried out by external forces operating in the system $V$.

The development of the equations presented in Oliveira [12] and Krahl et al. [13] started with the definition of a trigonometric function due to the degree of freedom $\left(\alpha_{1}\right)$, for the lateral displacement of the beam when in a condition of instability.

The general trigonometric function presented in Equation represents lateral rotation due to bending, where $\mathrm{L}$ is the length of the beam and $\alpha \mathrm{n}$ is a generalized variable that represents the maximum value of $u_{1}$, which is the lateral displacement of the beam. In the case of $n=1$, which represents the first buckling mode of rollover instability, the constant $\alpha 1$ is the maximum lateral displacement value in mid-span, and the curve is a single sine wave. Other buckling modes can be chosen for values higher than $\mathrm{n}$. In addition, Equation 1 satisfies the essential boundary conditions of the beam.

$$
u_{1}(x)=\sum_{n=0}^{m} \alpha_{n} \sin \left(\frac{n \pi x}{L}\right)
$$

The total internal energy of the system is presented Equation 2, including the energy from the rotation of support devices. Highlighted here is that lateral instability of precast beams occurs mainly due to a combination of lateral bending displacements and rigid body rotation.

$$
U=\frac{1}{2} \int_{0}^{L}\left(E I_{y} u_{1}^{\prime \prime 2}+G J \varphi_{1}^{\prime 2}+E I_{\omega} \varphi_{1}^{\prime \prime 2}\right) d x+k_{\theta} \varphi_{1}^{2}
$$

Where $E I_{y}, G J, E I_{\omega}$ are the stiffness to lateral bending, St. Venant torsion and warping, respectively. The last two forms of stiffness were functionally canceled due to twisting, $\varphi_{1}$ being assumed as constant (rigid body rotation). The parameter $k_{\theta}$ represents the rotational stiffness of the support devices and $u_{1}$ the lateral displacement of the beam. Approximate solutions for the stiffness of the support, which is nonlinear, were necessary for solving the problem. Rotations were considered constant over the interval with a value of $\varphi_{1}$.

In order to obtain the stability equation, the beam was considered as possessing an initial eccentricity $\left(e_{i}\right)$ and initial rotation $\left(\varphi_{0}\right)$, and that is was supported at its extremities by elastomeric pads, subject to its self-weight. Under the condition of instability, the beam presents lateral and vertical displacement due to bending, besides rigid body rotation.

The function that describes the initial eccentricity along the beam axis $\left(u_{0}\right)$ is calculated according to Equation 3 , where $e_{i}$ is the initial mid-span eccentricity.

$$
u_{0}(x)=e_{i} \sin \left(\frac{\pi x}{L}\right)
$$

The tipping action was given by the product of the vertical displacements by the respective loads applied to the structural element. Figure 3 presents the displaced beam configuration due to action resulting from own weight, acting on the center of mass during rollover of the beam with initial imperfections. 


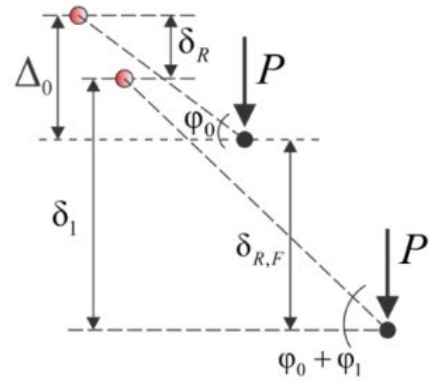

Centroid at supports

Centroid at midspan

Center of mass

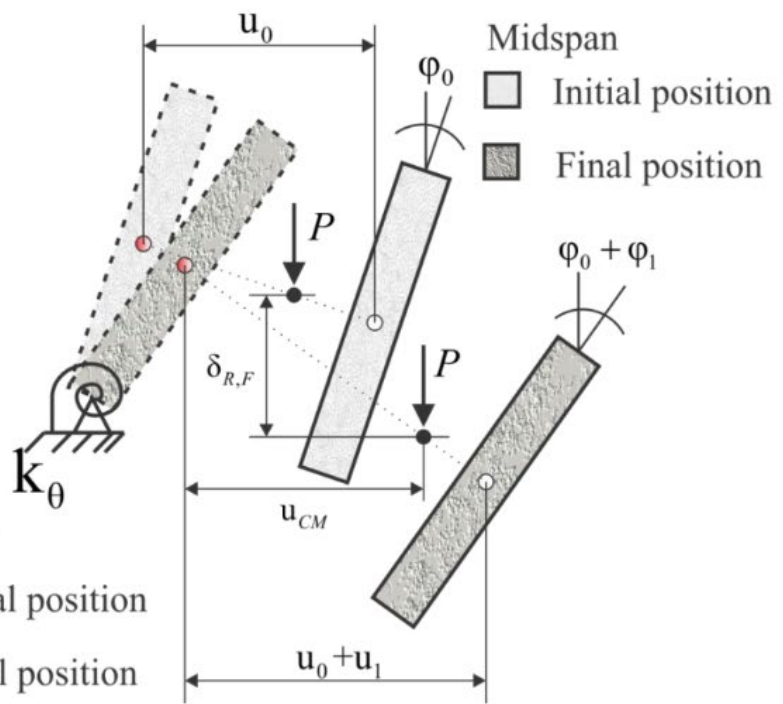

Figure 3. Trajectory of the resulting self-weight during rollover. Source: Adapted from Krahl et al. [13]

In Figure 3, one notes that the total vertical displacement of the mass center during rollover $\left(\delta_{R, F}\right)$ is a combination of three parts, the sum of $\delta_{R}$ with $\delta_{l}$, and subtracted the value of $\Delta_{0}$. As $\delta_{R}$ corresponds to the vertical movement of the mass center due to rotation of the rigid body of the beam, $\delta_{l}$ is the distance between the centroid on the supports and the mass center in the final position, and $\Delta_{0}$ represents the distance between the centroid on the supports and the mass center of the beam in the initial position. The generalized displacement $u_{0}$ represents the initial lateral displacement of the beam. The calculation of these displacements and the action performed by the result of self-weight is presented in Equations 4 to 7 in the following.

$\delta_{R}=2 y_{b} \sin ^{2}\left(\frac{\varphi_{1}}{2}\right)$

$\Delta_{0}=\frac{\tan \left(\varphi_{0}\right)}{L} \int_{0}^{L} u_{0} d x$

$\delta_{I}=\frac{\tan \left(\varphi_{0}+\varphi_{1}\right)}{L} \int_{0}^{L}\left(u_{0}+u_{1}\right) d x$

$V=-q L\left(\delta_{1}+\delta_{R}-\Delta_{0}\right)$

Where $\mathrm{y}_{\mathrm{b}}$ is the distance between the centroid of the beam and the axis of rotation located on the support device.

Through the minimization of the energy functional $(\Pi=U+V)$, it is possible to determine the solution for the degree of freedom $\alpha_{1}$ using Equation 8 and the critical load using Equation 9, thus obtaining the equation for final equilibrium (Equation 10).

$\alpha_{1} \rightarrow \frac{\partial}{\partial \alpha_{1}} \Pi=0$

$q \rightarrow \frac{\partial}{\partial \varphi_{1}} \Pi=0$ 
$q L\left\{2 y_{b} \sin \left(\frac{\varphi_{1}}{2}\right) \cos \left(\frac{\varphi_{I}}{2}\right)+\left[\frac{8 q L^{4} \tan \left(\varphi_{0}+\varphi_{1}\right)}{\pi^{6} E I_{y}}+\frac{2 e_{i}}{\pi}\right]\left[1+\tan ^{2}\left(\varphi_{0}+\varphi_{1}\right)\right]\right\}=2 k_{\theta} \varphi_{I}$

Equation 10 represents the nonlinear relationship between the force distributed along with the beam $q$ and the beam rotation $\varphi_{1}$ dependent on the initial rotation $\varphi_{0}$ and initial eccentricity $\mathrm{e}_{\mathrm{i}}$. When the initial rotation is considered equal to zero, the problem is reduced to the case of initial beam imperfection in the form of lateral displacement. If both initial rotation and displacement are equal to zero, the problem is reduced to the case of lateral instability of the perfect beam with flexible supports. In the latter case, it was possible to determine the critical force for lateral instability, under the hypothesis of rigid body rotation.

Noteworthy is that there exist trials that configure the transitory phase for which the formulation was developed. However, to validate the formula, Krahl et al. [13] linearized Equation 10 and compared it to solutions from Mast [1] and Burgoyne and Stratford [6]. The proposed equation presented results very close to those obtained by equations in the literature. In addition, Oliveira [12] compared the nonlinear solution to a simplified analytic strategy, which consisted of using a linear solution combined with the equation by Southwell [14]. The latter takes into account the linear tipping load and the initial imperfection to obtain the nonlinear response. The results were identified until the peak. However, the equation by Southwell [14] did not predict the unstable behavior of the post-peak, which is characteristic of the problem with high sensitivity to initial imperfection.

\subsection{Determining initial cracking}

According to Mast [1], the cracking of concrete can be admitted as a limit state on the lateral stability of beams. Even though it is understood that prestressing does not influence in the tipping of the beam, the stresses developed due to prestressing should be considered to check for possible cracking. Therefore, the tensile stress critical for cracking $\sigma_{\mathrm{t}, \text { crit }}$ was determined in the mid-span section for each rotation angle $\varphi_{1}$, as shown in Figure 4.

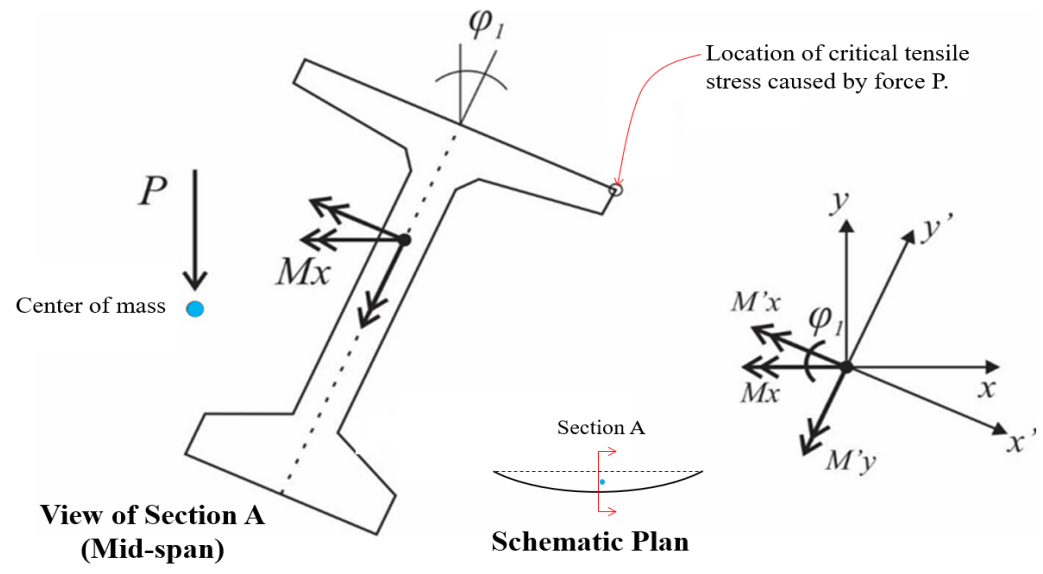

Figure 4. Decomposition for checking the cracking moment. Source: Adapted from Oliveira [12]

The flexibility of the supports during tipping allows one to ignore the effects of twisting. Equation 11 presents the general expression for determining the stress on the cross-section at the mid-span. The compressive stresses were admitted as negative and the bending moments are designated according to the right-hand rule, where $\mathrm{F}$ is the prestressing force, A the section area, e the prestress eccentricity, $\mathrm{M}^{\prime}{ }_{\mathrm{x}}$, and $\mathrm{M}_{\mathrm{y}}{ }_{\mathrm{y}}$ are the components of the moment caused by the distributed vertical force, $x$ ' and $y$ ' are the coordinates of the point of interest on the rotation axis, $I^{\prime}{ }_{x}$ and $\mathrm{I}_{\mathrm{y}}$ are the inertia moments that also correspond to the rotated axis, and Mx is the moment due to the own weight of the beam.

$\sigma=-\frac{F}{A}+\frac{F e y^{\prime}}{I_{x}^{\prime}}-\frac{M_{x}^{\prime} y^{\prime}}{I_{x}^{\prime}}+\frac{M_{y}^{\prime} y^{\prime}}{I_{y}^{\prime}}$ 
$M_{x}^{\prime}=M_{x} \cos \left(\varphi_{1}\right)$

$M_{y}^{\prime}=M_{x} \sin \left(\varphi_{1}\right)$

The nonlinear equation (Equation 10) allows one to determine the resulting moment Mx and its components $\mathrm{M}_{\mathrm{x}}$. and $\mathrm{M}_{\mathrm{y}}^{\prime}$ acting on the mid-span for each value of $\varphi_{1}$ and corresponding force $q$. Following this, the stresses can be calculated according to Equation 11, and the critical cracking load $\mathrm{q}_{\mathrm{cr}}$ can be obtained when $\sigma$ reaches the reaches concrete tensile strength $f_{t}$. Such strength can be estimated according to ABNT NBR 6118:2014 [15] as $f_{c t}=0.3 f_{c k}{ }^{2 / 3}$, where fck is the characteristic compressive strength of concrete.

\section{DEVELOPMENT OF THE ALGORITHM AND PARAMETRIC ANALYSIS OF THE ANALYTIC SOLUTIONS}

\subsection{Development of the algorithm}

The parametric study was developed to verify the mechanical component, considering the variation over specific properties of the beam. The method is based on a large number of random samples for evaluating the variation of parameters associated with the model in the mechanical response of the structure. This procedure was developed employing computer programming using the language Python.

To obtain the random sample, for each of the parameters analyzed, 100 thousand simulations are performed. In each simulation, a random value is attributed to the following variables, initial lateral eccentricity, modulus of elasticity of concrete and stiffness to the rotation of the support. These parameters were not variable only when they are the parameter of analysis under focus.

The random values were obtained in the following way, the initial lateral eccentricity and the modulus of elasticity were adopted randomly, according to the normal distribution, for which the average was the value of the default input. The variation coefficient was 0.61 for the initial eccentricity [16] and 0.15 for the modulus of elasticity [17]. In order to take into account the effect from the loss of contact and the possible curve at the bottom flange of the beam in contact with the bearing pad, the variation in stiffness to the rotation of the support device was considered randomly from $25 \%$ to $100 \%$ of the total stiffness established as the default input value. The default data values of the problem were attributed based on the beam in the trial by Hurff and Kahn [11].

The stiffness to the rotation of the support device was calculated by Equation 12. The axial stiffness of the support device (Equation 13) was calculated according to that proposed by Yazdani et al. [18].

$k_{\theta}=\frac{k_{v} L_{a}^{2}}{12}$

$k_{v}=\frac{E_{p a d} L_{a} W_{a}}{H_{a}}$

Epad $=6$. Gpad.$S^{2}$

$S=\frac{(n i \cdot h i \cdot S 1)+(n e \cdot h e \cdot S 2)}{(n i \cdot h i)+(n e \cdot h e)} ; S 1=\frac{L_{a} \cdot W_{a}}{2 \cdot h i \cdot\left(L_{a}+W_{a}\right)} ; S 2=\frac{L_{a} \cdot W_{a}}{2 \cdot h e \cdot\left(L_{a}+W_{a}\right)}$

With $k_{v}$ the stiffness to compression of the pad, $L_{a}, W_{a}$ and $H_{a}$ the dimensions of the pad, Ead the modulus of elasticity of the pad, $G_{p a d}$ the shear modulus of the pad, $n i$ and $n e$ the number of internal and external layers of the pad respectively, $h i$ and $h e$ the height of the internal and outer layers of the pad respectively.

The precision of the rigid body rotation angle from the analyses was $0.001 \mathrm{rad}$. The modulus of elasticity, and $\mathrm{fta}_{\mathrm{ct}}$ are determined from concrete compressive strength $f_{\text {ck }}$, according to the formulations from ABNT NBR 6118:2014 [15]. 
The cross-section stress curve depends on two parameters, the acting force and the rotation angle. The values for the acting force are obtained by Equation 10. With the definition of the stress curve at hand, the value for stress closest to fct, was determined, in this way, the load and the angle corresponding to this point are the critical values for the initial cracking of the beam. The structure of the algorithm developed and programmed herein is presented in Figure 5.

\subsection{Parametric analysis results}

The parametric analysis is performed to verify the behavior of the beam for the variation of parameters indicated in Table 1. The properties of the beam used as the basis for the parametric analysis are presented in Table 2 . The initial rotation of the beam of $0.5^{\circ}$ was considered and an initial eccentricity of $\mathrm{L} / 1000$.

The support device was considered according to the study by Hurff and Kahn[11] with dimensions of $61 \times 36 \times 7.3 \mathrm{~cm}^{3}$ composed of 4 steel sheets, three internal elastomeric layers of $15 \mathrm{~mm}$ each and two external elastomeric layers of $7.5 \mathrm{~mm}$ each, as outlined in Figure 6.

For the stiffness to rotation calculation, the modulus of elasticity to the shear of the support apparatus was used at $670 \mathrm{kPa}$, which resulted in a rotational stiffness of $33.4 \mathrm{MNm} / \mathrm{rad}$.

Table 1. Data for the parametric analysis

\begin{tabular}{ll}
\hline \multicolumn{1}{c}{ ANALYSIS PARAMETER } & VALUES ANALYZED \\
\hline Initial eccentricity & $\mathrm{L} / 1000 ; \mathrm{L} / 500 ; \mathrm{L} / 250 ; \mathrm{L} / 125$ \\
\hline Initial Rotation & $0.5^{\circ} ; 1.5^{\circ} ; 3.0^{\circ}$ \\
\hline Concrete strength & $50 \mathrm{MPa} ; 75 \mathrm{MPa} ; 100 \mathrm{MPa}$ \\
\hline Support pad dimension & $61 \times 36 \times 7.3 \mathrm{~cm}^{3} ; 61 \times 36 \times 9.8 \mathrm{~cm}^{3} ; 61 \times 36 \times 12.3 \mathrm{~cm}^{3}$ \\
\hline Beam cross section $\left(^{*}\right)$ & $\mathrm{BT}-54 ; \mathrm{BT}-63 ; \mathrm{BT}-72$ \\
\hline * For each of the three cross-sections of the beam, three cases are analyzed, modifying the dimension of the top flange, with $100 \%$ \\
of the standard value; $50 \%$ of the standard value; and with length equal to the thickness of the web.
\end{tabular}

Source: Authors.

Table 2. Properties of the base beam parametric analysis

\begin{tabular}{lc}
\hline Moment of inertia in relation to the $\mathrm{X}$-axis $\left(\mathrm{I}_{\mathrm{x}}\right)$ & $0.1116 \mathrm{~m}^{4}$ \\
\hline Moment of inertia in relation to the $\mathrm{Y}$-axis $\left(\mathrm{I}_{\mathrm{y}}\right)$ & $0.0155 \mathrm{~m}^{4}$ \\
\hline Beam height $(\mathrm{h})$ & $1.372 \mathrm{~m}$ \\
\hline Height of center of gravity $(\mathrm{yb})$ & $0.703 \mathrm{~m}$ \\
\hline Width of the top flange (MS) & $1.067 \mathrm{~m}$ \\
\hline Area of cross-section (A) & $0.425642 \mathrm{~m}^{2}$ \\
\hline Beam length (L) & $30.5 \mathrm{~m}$ \\
\hline Modulus of elasticity of concrete (E) & $30820 \mathrm{MPa}$ \\
\hline
\end{tabular}

Source: Oliveira [12]

Brazilian standards indicate the shear modulus of elasticity or the minimum transverse deformation modulus of $0.80 \mathrm{MPa}$ [19] and 0.85 $\mathrm{MPa}$ [20], as such the value of $0.67 \mathrm{MPa}$ was adopted following the studies [10]-[13]. Figure 7 presents the nonlinear curve obtained by Equation 10 for the force values due to the rigid body rotation of the beam. For these data, in absolute values without any variation, the values of $339.87 \mathrm{kN} \cdot \mathrm{m}$ for maximum strength and of $0.16041 \mathrm{rad}$ were obtained for the rotation angle that corresponds to this strength.

The strength at initial cracking is of $339.85 \mathrm{kN} \cdot \mathrm{m}$, with an angle of $0.16642 \mathrm{rad}$. For this particular case, the loads for cracking and rollover were very close, justifying in this way the direct use of Equation 10 in the verification of lateral instability through rollover, while considering the concrete with a linear behavior. This hypothesis has been found in numerical simulations presented in the literature [2], [9], [10], [21]. Also, the emphasis is given to the fact that the formulation can identify the maximum strength value, as it presents unstable post-peak behavior. 


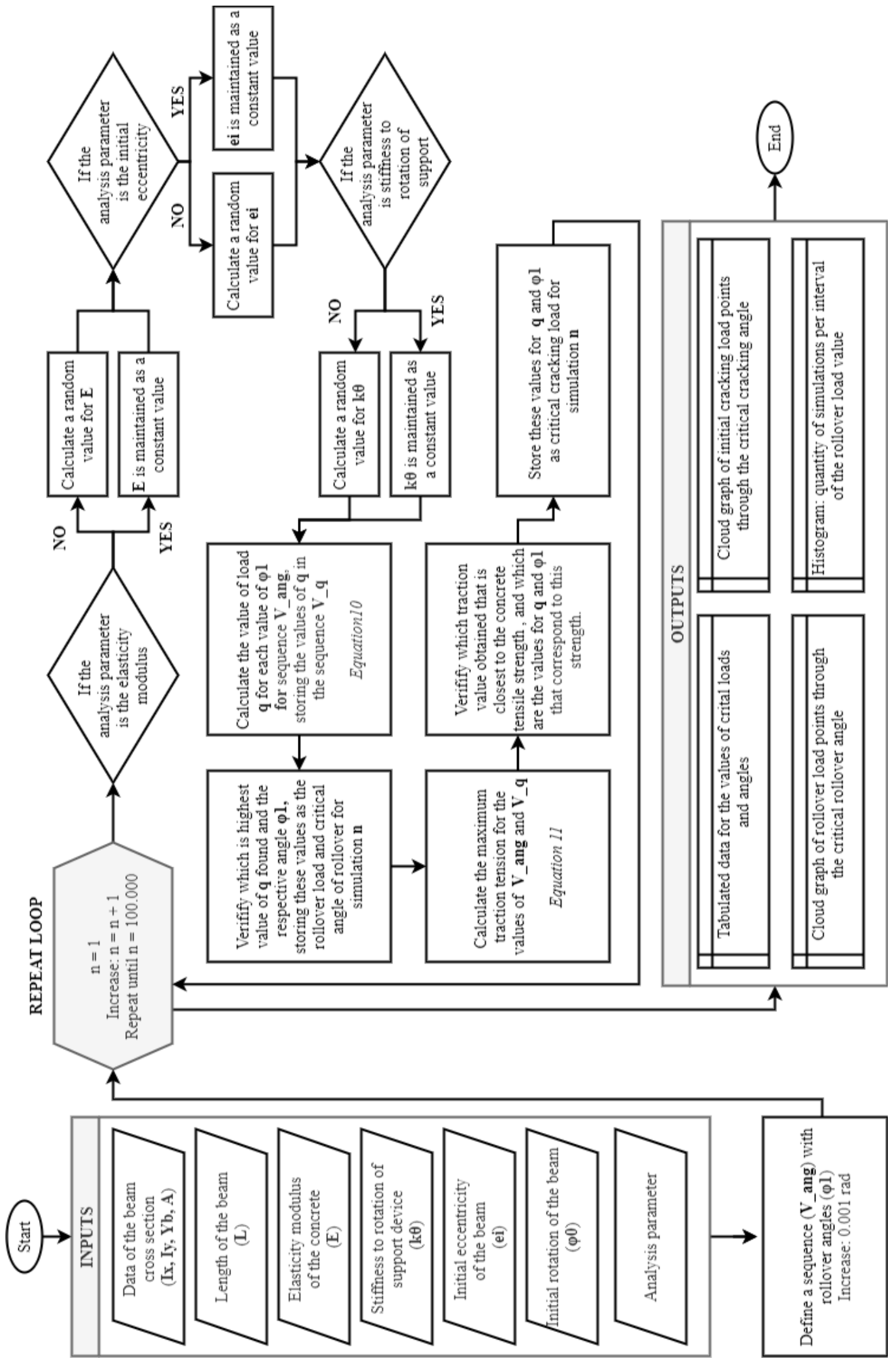

Figure 5. Structure of the parametric analysis algorithm. Source: Authors. 


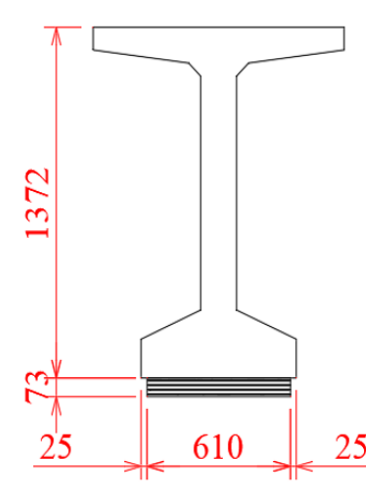

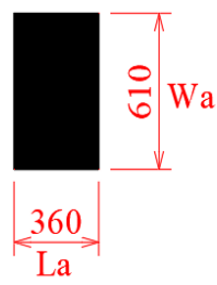

PAD DIMENSIONS

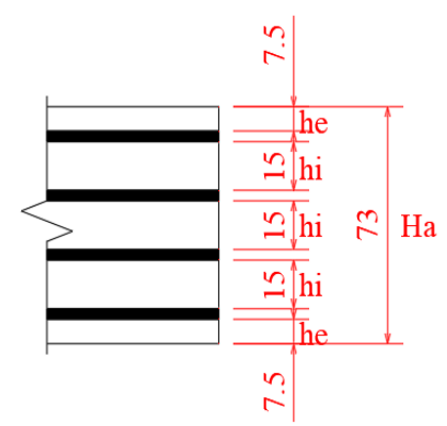

HEIGHTS OF PADS

VIEW OF BEAM ON BEARING PAD

Figure 6. Schematic representation of the bearing pad. Units in [mm]. Source: Authors.

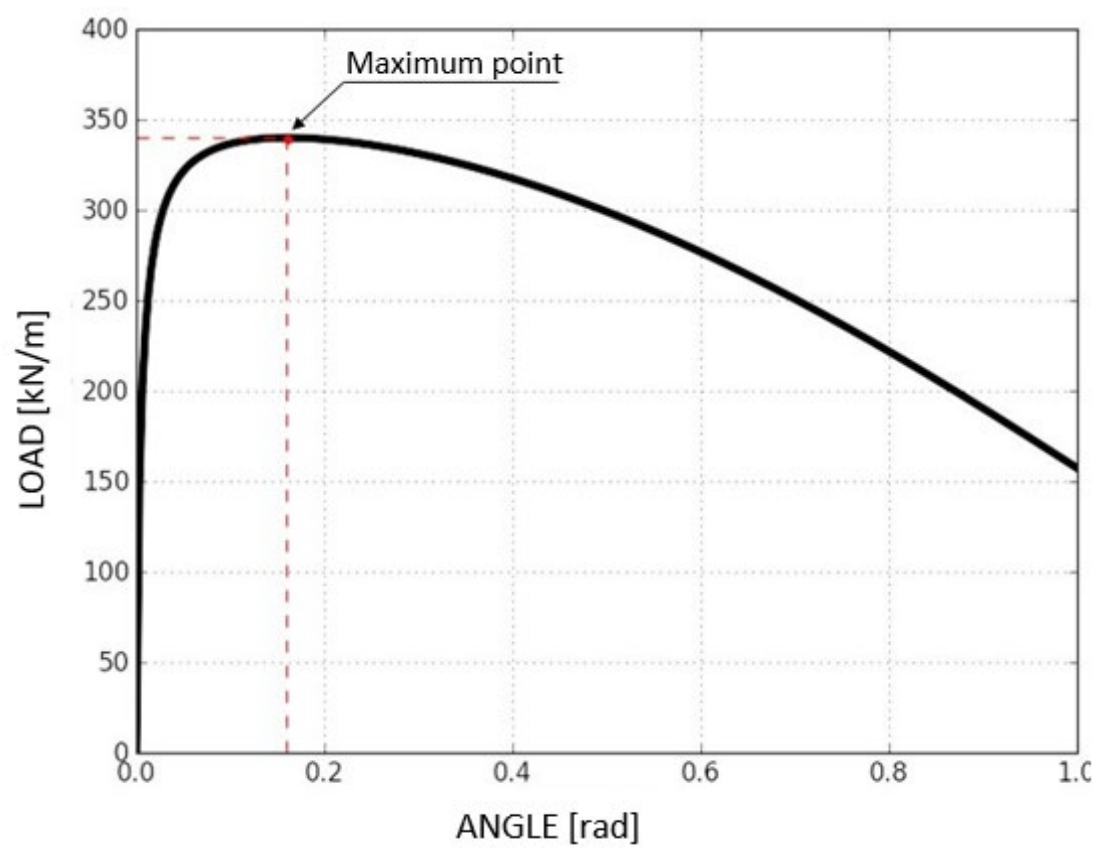

Figure 7. Load applied by the stiffness to the rotation angle of the beam. Source: Oliveira [12]

Figure 8a represents the value of maximum strength and the respective rollover angle for each of the 100 thousand simulations obtained through Equation 10, considering the randomness of the variables mentioned above, in. Noteworthy here is that the random values for initial lateral eccentricity and the modulus of elasticity were adopted while considering a normal distribution with a coefficient of variation of 0.61 for initial eccentricity and 0.15 for the modulus of elasticity of the concrete. In terms of support stiffness, the random values vary from $25 \%$ to $100 \%$ of the total rigidity established as the default value. The same was performed while considering the force for the initial cracking of the beam in Figure 8 b.

The histogram of Figure $8 \mathrm{c}$ refers to the results presented in Figure 8a, where these values were arranged to represent the number of simulations that give the value of maximum strength during a defined interval. Therefore, the $\mathrm{x}$-axis represents the maximum strength intervals considered and the y-axis the number of simulations that result in the maximum strength in this interval. 


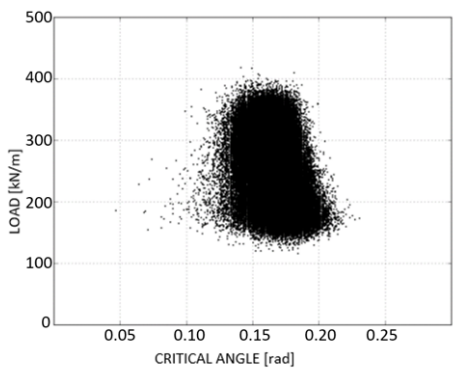

(a) Maximum beam load with initial eccentricity and initial rotation

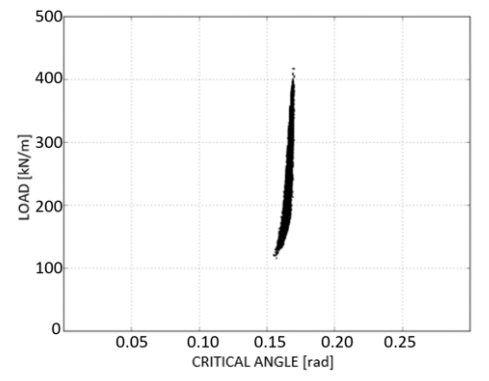

(b) Load at initial cracking for the beam with initial eccentricity and initial rotation angle

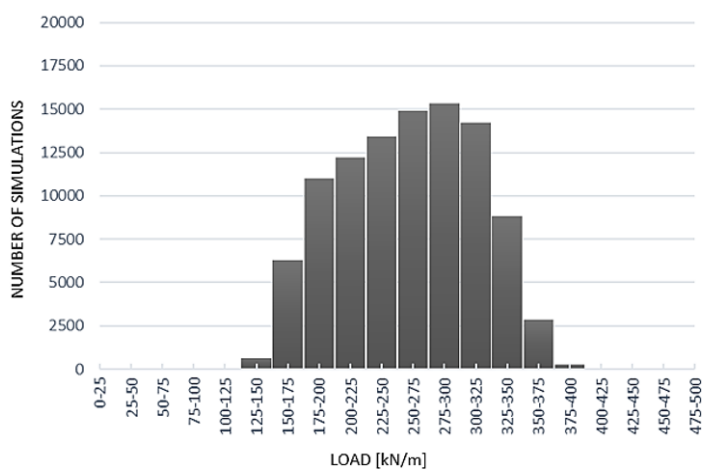

(c) Histogram of maximum beam strength with initial eccentricity and initial rotation of base data

Figure 8. Results of base data for beam with initial eccentricity and initial rotation angle. Source: Oliveira [12]

The result from the direct application of the equation is a maximum strength of $339.87 \mathrm{kN} / \mathrm{m}$ (Figure 7). For the analysis with statistical variations of the parameters, considering the 100 thousand simulations, one notes that for the strength value obtained in the interval of $325-350 \mathrm{kN} / \mathrm{m}$, which represents a portion around the mark of 9 thousand simulations. However, the majority of the simulations, around 15 thousand simulations, had a result of maximum strength between 275 and $300 \mathrm{kN} / \mathrm{m}$. For these base values, regarding the 100 thousand simulations, the most significant values for maximum strength vary from 175 to $350 \mathrm{kN} / \mathrm{m}$, which corresponds to $90 \%$ of the total simulations.

In these simulations, randomness occurs from the combination of random values for the initial lateral eccentricity and the elasticity modulus, while considering a normal distribution with a coefficient of variation of 0.61 for the initial eccentricity and 0.15 for the modulus of elasticity of the concrete; for support stiffness, the random values vary from $25 \%$ to $100 \%$ of the total stiffness established as a default value.

The average rollover load value obtained from Figure $8 \mathrm{a}$ is of $258.49 \mathrm{kN} / \mathrm{m}$. by comparing this result to the value of critical force obtained without considering the variation of the parameters, a reduction of $23.9 \%$ was observed, which corresponds to a reduction factor of 1.3. Besides, the fact that one is dealing with the verification of safety in structures, it is common knowledge that statistically, the resistances are considered as holding characteristic values. As such, a normal resistance distribution was considered typically as that presented in Figure 8c, and assumed as a characteristic value is a portion (quantile) of the distribution that represents a degree of confidence, for example, of $95 \%$. This would result in a critical rollover load that is still less than the average. Therefore, the emphasis is placed upon the importance of considering the high degree of uncertainty associated with this transitory phase. Despite the analyzed variability, the beam in question remains stable, since the load due to own weight is of the order of $10 \mathrm{kN} / \mathrm{m}$, and the rollover or cracking loads were above $100 \mathrm{kN} / \mathrm{m}$, which would result in a safety coefficient above 10 .

\subsubsection{Initial Lateral Eccentricity}

The first parameter analyzed refers to the influence of the initial lateral eccentricity of the beam, where the following values were considered $\mathrm{L} / 1000, \mathrm{~L} / 500, \mathrm{~L} / 250$ and $\mathrm{L} / 125$, where $\mathrm{L}$ is the length of the beam. For this analysis, eccentricity is maintained constant, equal to the value analyzed, without the attribution of random values to this parameter as in the other analyses. Figure 9 illustrates the results for this analysis. 
This variable reduces the strength limit with the increase of the critical rotation angle. In the critical cracking strength, the angle obtained was practically the same for the four values observed for eccentricity, a general average of 0.166 radians. The average critical strength suffers a reduction of approximately $1 \%$ and the average critical angle increases by almost $11 \%$ for the increase in the initial eccentricity from $\mathrm{L} / 1000$ to $\mathrm{L} / 500$. However, the increase in eccentricity from $\mathrm{L} / 1000$ to $\mathrm{L} / 250$, the reduction was $3 \%$ in critical strength with an increase of $27 \%$ in the angle from $\mathrm{L} / 1000$ to $\mathrm{L} / 125$, and the reduction was of nearly $7 \%$ in strength and an increase of $57 \%$ in the angle. Under these terms, it became clear that the eccentricity increases the susceptibility significantly for lift-off, which is the loss of contact between the beam and the support device.

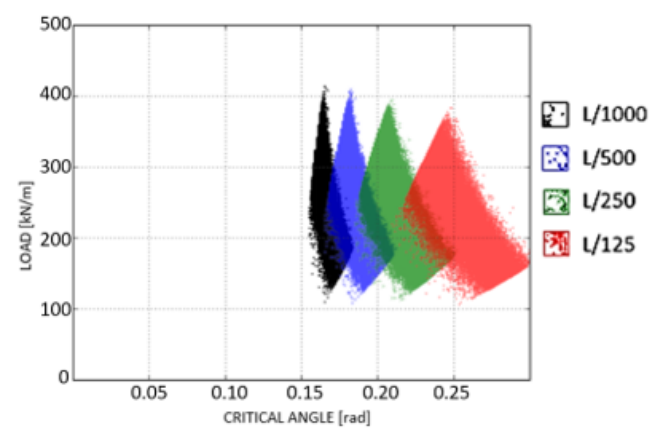

(a) Maximum load of the beam with initial eccentricity
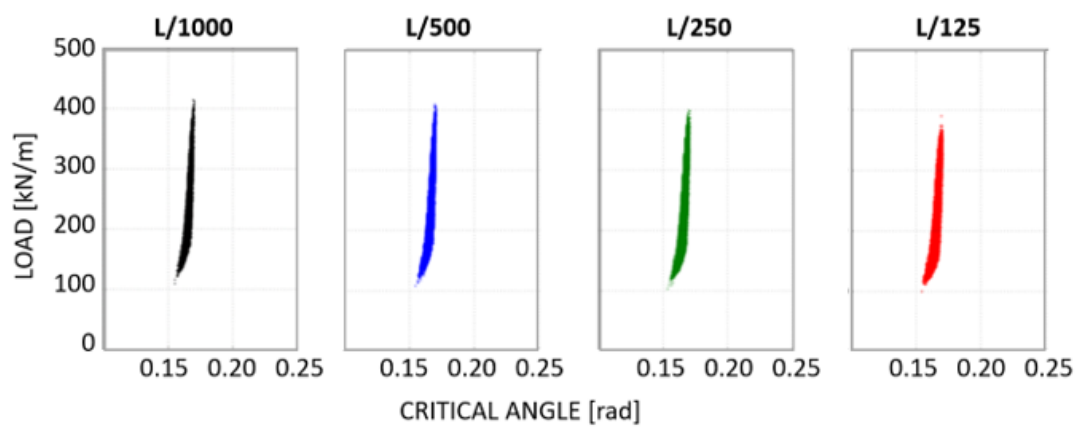

(b) Load at cracking of the beam with initial eccentricity

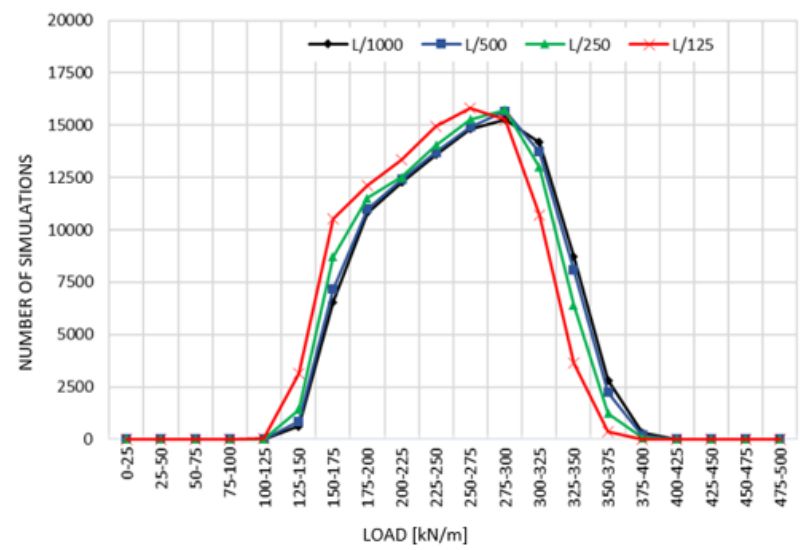

(c) Histogram of the influence from initial eccentricity on maximum strength of the beam

Figure 9. Variation of initial lateral eccentricity. Source: Oliveira [12]

Therefore, the increase of initial eccentricity was causing a reduction in critical rollover load, followed by the rise in critical rotation. However, although the critical load at the beginning of cracking is less with the increase in eccentricity, the cracking angle presented values very close to one another, as seen in Figure $9 \mathrm{~b}$. 


\subsubsection{Initial rotation}

Another parameter of the initial imperfection of the beam that may influence lateral instability was the existence of initial rotation around its longitudinal axis. To observe the influence of this variable (Figure 10), three values of angle are adopted, such as $0.5^{\circ}(0.008727 \mathrm{rad}), 1.5^{\circ}(0.02618 \mathrm{rad})$ and $3^{\circ}(0.05236 \mathrm{rad})$. Highlighted here is that the study interval was adopted based on the results presented in [12] since these can produce instability on the beam.

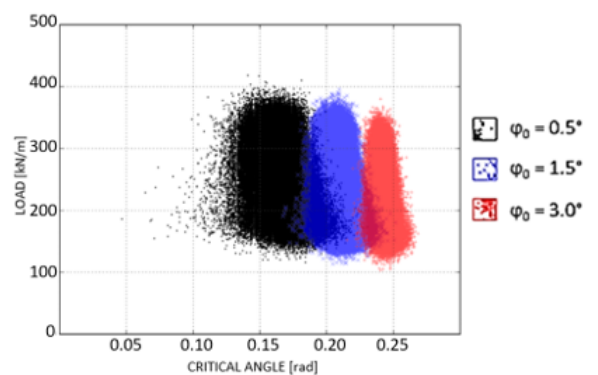

(a) Maximum load of the beam with an initial rotation angle

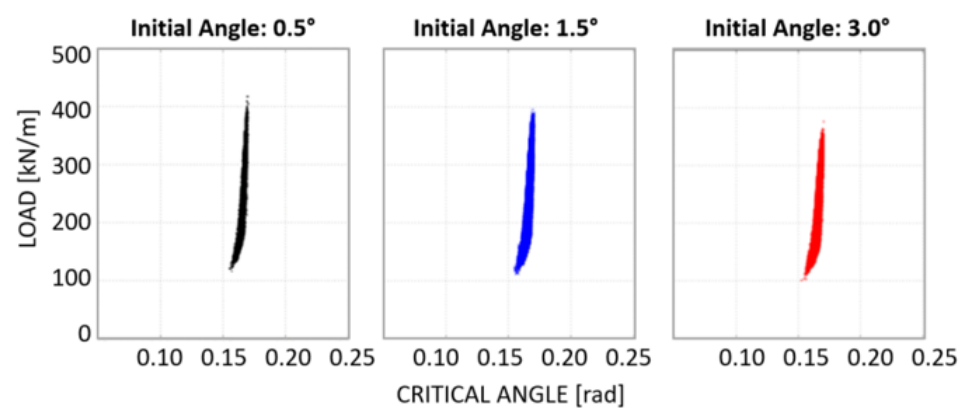

(b) Load at initial cracking of the beam with an initial rotation angle

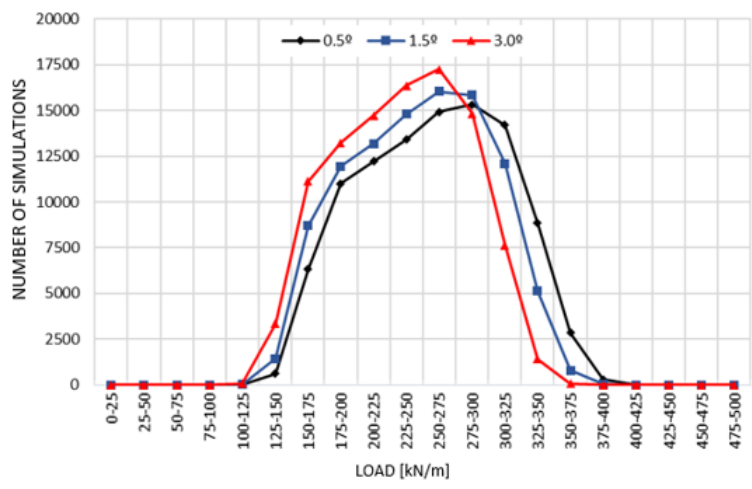

(d) Histogram of the influence from initial rotation on the maximum load of the beam

Figure 10. Variation of the initial rotation. Source: Oliveira [12]

The increase in the initial rotation of the beam brought about a decrease of the maximum strength value, as the critical rotation angle increased.

Noted in Figure 10a is that for an initial rotation angle less than $\left(0.5^{\circ}\right)$, there was a significant variation in the critical angle, but for the larger angle $\left(3.0^{\circ}\right)$, the results are more concentrated close to the average angle of 0.24 radians. In terms of the critical cracking force (Figure 10b), the critical angle was practically the same for the four values observed, with an overall average of 0.166 radians.

\subsubsection{Compressive strength of concrete}

For the analysis of the influence of the compressive strength of concrete, three concrete compressive strength values were assigned (fck), those being: $50 \mathrm{MPa}(\mathrm{E}=39597.98 \mathrm{MPa}), 75 \mathrm{MPa}(\mathrm{E}=48497.42 \mathrm{MPa})$ and $100 \mathrm{MPa}$ $(\mathrm{E}=56000.00 \mathrm{MPa})$. The tangent modulus of elasticity was considered in a simplified form, where it was calculated 
by $\mathrm{E}=5600 \sqrt{f_{c k}}$. For each value of fck, its elasticity modulus was maintained constant, without the assigning of random values to this parameter as performed in other analyses. Figure 11 presents the results of this analysis.

In this analysis, the significant influence exerted by the modulus of elasticity of the concrete on the lateral stability of the beam became evident. The elasticity modulus can be related to the compressive strength of the concrete. The higher the compressive strength of the concrete, the greater will be the stability of the system, in such a way that there is a substantial increase in critical stress.
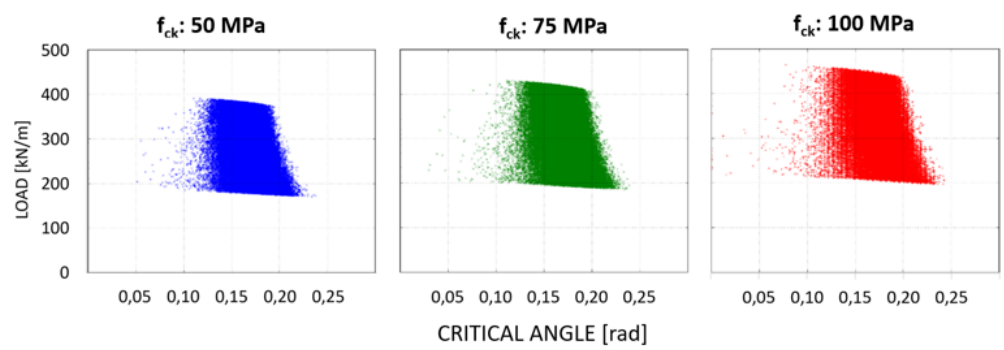

(a) Maximum load of the beam due to characteristic resistance of concrete compression
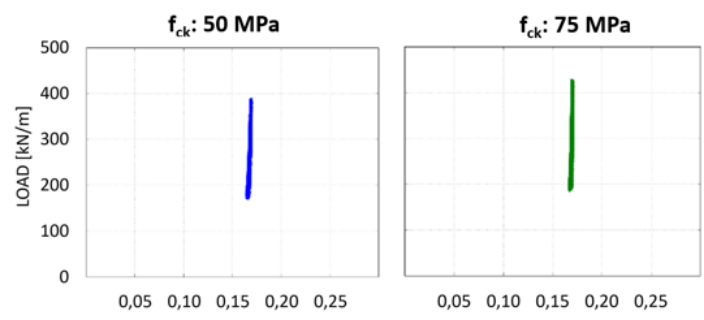

$\mathrm{f}_{\mathrm{ck}}: 100 \mathrm{MPa}$

(b) Load at initial cracking of the beam due to characteristic resistance to concrete compression

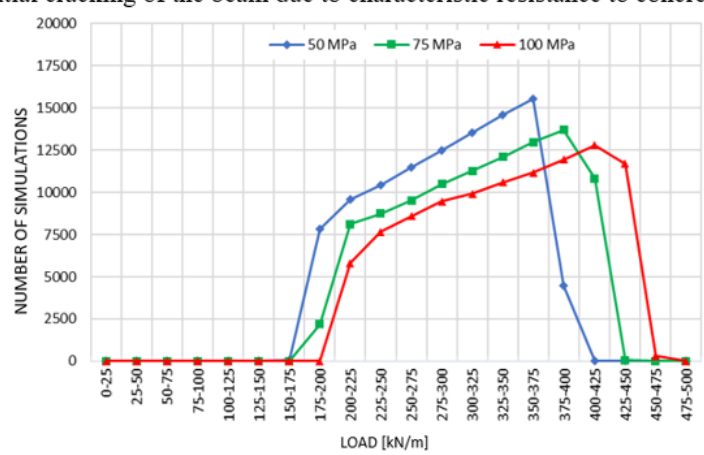

(c) Histogram of the influence from concrete resistance on the maximum load of the beam

Figure 11. Variation of the characteristic resistance to concrete compression. Source: Oliveira [12]

Despite the increase in critical stress, the variation of the corresponding critical angles was minimal. As such, the conclusion was reached that the compressive strength of the concrete of the beam directly influences in the critical stress (Figure 11c), but the rollover angle (Figure 11a), and initial cracking (Figure 11b) was influenced very little.

\subsubsection{Stiffness of the support device}

The stiffness of the support device can have a significant influence over the lateral stability of the beams. To consider the variation and the importance of this parameter in the analyses, a variation of $25 \%$ to $100 \%$ of the initial value was considered for the pad, where $100 \%$ was considered the total stiffness value. Brazilian standards [19] and [20] do not establish limits or calculation methods for the stiffness to the rotation of the support device. In addition, the dimensions of the support device do not possess high flexibility to modification, since these are limited due to the maximum compression admitted by the standards and the dimensions of the bottom flange of the beam. The arrangement of the pad can bring about modifications to the rotation stiffness associated with it. Thus, the influence of this parameter on the lateral stability of the beam will be analyzed in this section.

In the first analysis, the initial dimensions of the support device are considered as $610 \times 360 \times 73 \mathrm{~mm}$, with four steel sheets, three internal layers of elastomer of $15 \mathrm{~mm}$ each and two external layers of elastomer of $7.5 \mathrm{~mm}$ each. According to that presented 
in Figure 6, the calculated stiffness to the rotation was equal to $33366.66 \mathrm{kN} / \mathrm{m} \cdot \mathrm{rad}$. In the second analysis, an increase of $5 \mathrm{~mm}$ was considered for each layer of elastomer, thus resulting in a pad of $610 \times 360 \times 98 \mathrm{~mm}$ and stiffness of $12384.38 \mathrm{kN} / \mathrm{m} \cdot \mathrm{rad}$ (37.1\% of the initial stiffness). In the third analysis, the increase considered was $10 \mathrm{~mm}$ for each layer, resulting in dimensions of $610 \times 360 \times 123 \mathrm{~mm}$ and stiffness of $5891.79 \mathrm{kN} / \mathrm{m} \cdot \mathrm{rad}$, which corresponds to $17.7 \%$ of the initial stiffness analyzed.

The increase in the height of the pads was attributed in a way to significantly modify the stiffness to rotation values of the support device, aiming at a better view of its influence. Such values do not correspond to the tolerance limits accepted by Brazilian standards [19] and [20] since these limits are $5 \mathrm{~mm}$ for the width and length of the bearing pad and between $1 \mathrm{~mm}$ and $3 \mathrm{~mm}$ for the height of the pad. Figure 12 shows the results of this analysis that refer to maximum load, initial load at cracking and the histogram of the number of simulations due to the maximum load for each situation of support device stiffness. With the increase of stiffness, besides the increase in critical load, there was a considerable variation on the critical rollover angle (Figure 12a), which is characteristic of a more unstable system. By taking the stiffness to rotation as a fixed parameter, a lower variation of critical load values occurred, which is noted when one compares the graph from Figure 12a with the first graphs of the previous analyses (Figures 8a, 9a, 10a and 11a). The tendency found was that the critical angle approximate to 0.15 radians, as the pad becomes stiffer. Despite the significant variation in the cracking load values, its initiation maintained the tendency of critical angle with values close to 0.16 radians, for the three observed cases.
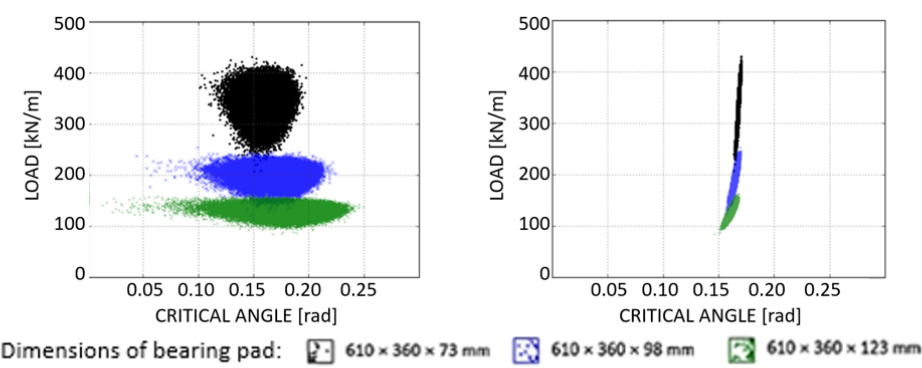

(a) Maximum load of the beam with pad stiffness variation

(b) Load at initial cracking of the beam due to pad stiffness

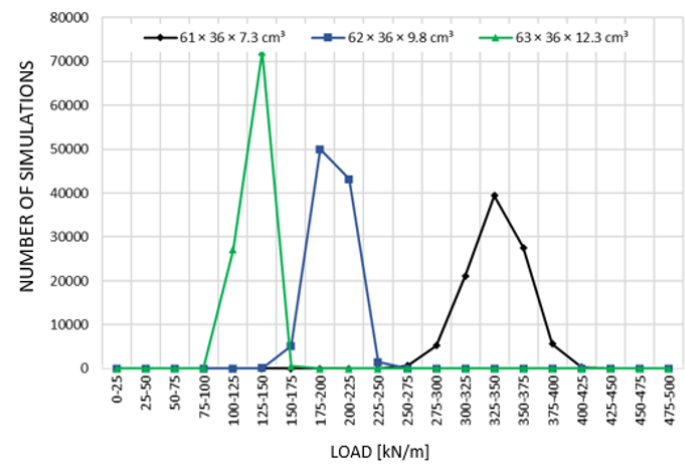

(c) Histogram of the influence of pad stiffness on the maximum load of the beam

Figure 12. Variation of the stiffness of the bearing pad. Source: Oliveira [12]

\subsubsection{Cross-section of the beam}

The cross-section of the beam in this study was analyzed also considering the possibility of reducing the width of the top flange. In the first analysis, the cross-section and the span of the beam were modified, while maintaining the relationship between the height of the beam and the span proportional. Therefore, the sections BT-54, BT-63 and BT-72 are analyzed with the lengths of $30.5 \mathrm{~m}, 35 \mathrm{~m}$ and $40 \mathrm{~m}$, respectively. The beams classified in the technical literature as BT-54, BT-63 and BT-72 refer to standard cross-sections from PCI (Precast/Prestressed Concrete Institute), widely used in the construction of bridges and viaducts from precast concrete, and the aim of analyses in Lee [9], Krahl et al. [10], Hurff and Kahn [11] and Oliveira [12]. In the second analysis, the influence of slenderness and the lateral moment of inertia were studied about the Yaxis, by modifying the width of the top flange. The top flanges were considered using $100 \%$ of the original value, $50 \%$ of this value and under a condition where the top flange possesses a width equal to the thickness of the web. Figure 13 and Table 3 present the properties of the beams studied. 


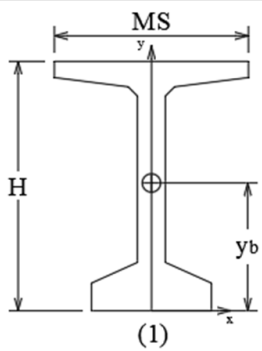

(a) Case (1) $-100 \%$ of the width of the top flange

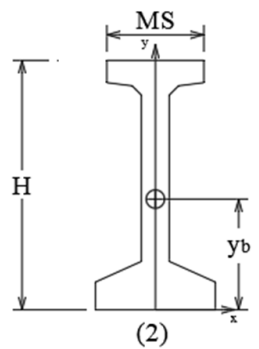

(b) Case (2) $-50 \%$ of the width of the top flange

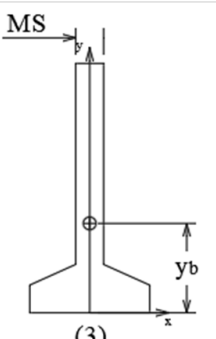

(3)

(c) Case (3) - width of the top

flange equal to the width of the web

Figure 13. Cross-sections of the beams with modifications to the width of the top flange. Source: Oliveira [12]

Table 3. Properties of the beams of the series PCI-BT

\begin{tabular}{|c|c|c|c|c|c|c|c|c|c|c|}
\hline & & \multicolumn{3}{|c|}{ BT-54 } & \multicolumn{3}{|c|}{ BT-63 } & \multicolumn{3}{|c|}{ BT-72 } \\
\hline & & Case (1) & Case (2) & Case (3) & Case (1) & Case (2) & Case (3) & Case (1) & Case (2) & Case (3) \\
\hline Moment of inertia $\mathrm{Y}$ axis & Iy $\left[\mathrm{m}^{4}\right]$ & 0.01550 & 0.00649 & 0.00486 & 0.01560 & 0.00656 & 0.00493 & 0.01570 & 0.00663 & 0.00499 \\
\hline Moment of inertia $\mathrm{X}$ axis & Ix $\left[\mathbf{m}^{4}\right]$ & 0.11157 & 0.08687 & 0.05690 & 0.16340 & 0.12907 & 0.08817 & 0.22739 & 0.18188 & 0.12856 \\
\hline Length of beam & $\mathbf{L}[\mathbf{m}]$ & 30.50 & 30.50 & 30.50 & 35.00 & 35.00 & 35.00 & 40.00 & 40.00 & 40.00 \\
\hline Height of center gravity & $\mathbf{y}_{\mathbf{b}}[\mathbf{m}]$ & 0.703 & 0.609 & 0.492 & 0.817 & 0.715 & 0.591 & 0.931 & 0.822 & 0.693 \\
\hline Height of beam & $\mathbf{H}[\mathbf{m}]$ & 1.372 & 1.372 & 1.372 & 1.600 & 1.600 & 1.600 & 1.829 & 1.829 & 1.829 \\
\hline Width of top flange & MS [m] & 1.067 & 0.5335 & 0.153 & 1.067 & 0.5335 & 0.153 & 1.067 & 0.5335 & 0.153 \\
\hline Area of cross section & $A\left[\mathbf{m}^{2}\right]$ & 0.42564 & 0.36922 & 0.31579 & 0.46062 & 0.4042 & 0.35076 & 0.49566 & 0.43924 & 0.3858 \\
\hline Slenderness & & 31.08 & 78.33 & 414.15 & 37.55 & 94.61 & 500.25 & 44.87 & 113.05 & 597.78 \\
\hline
\end{tabular}

Source: Oliveira [12]

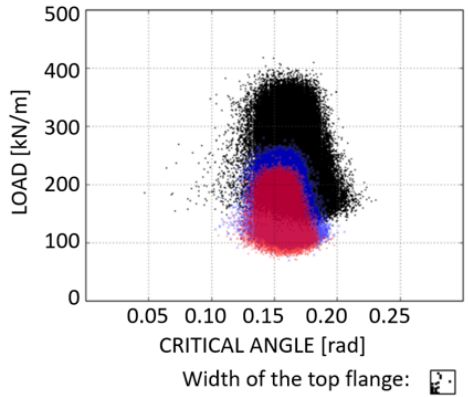

(a) Maximum load of the beam with width variation of the top flange for base BT-54

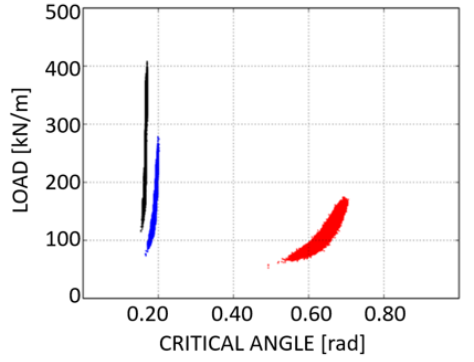

$1.062 \mathrm{~m}$ 圆 $0.5335 \mathrm{~m}$ 圈 $0.153 \mathrm{~m}$

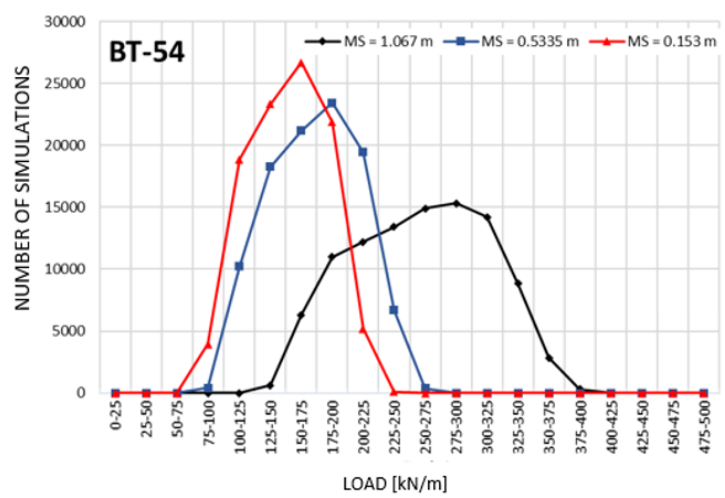

(c) Histogram of the influence of the top flange on the maximum load for beam base BT-54

Figure 14. Beam BT-54 with width variation of the top flange. Source: Oliveira [12] 


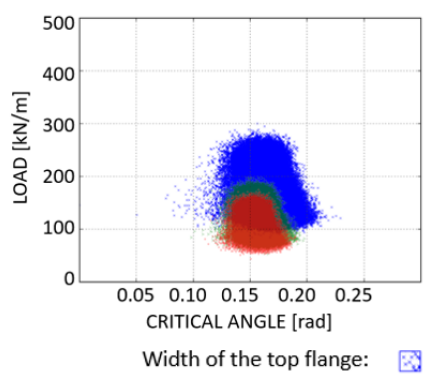

(a) Maximum load of the beam with width variation of the top flange for base BT-63

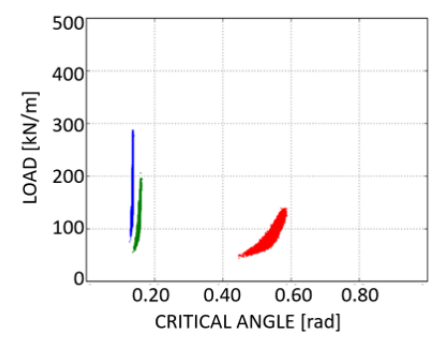

$0.5335 \mathrm{~m}$ 稀 $0.153 \mathrm{~m}$

(b) Load at initial cracking of the beam due to the width of the top flange for beam base BT-63

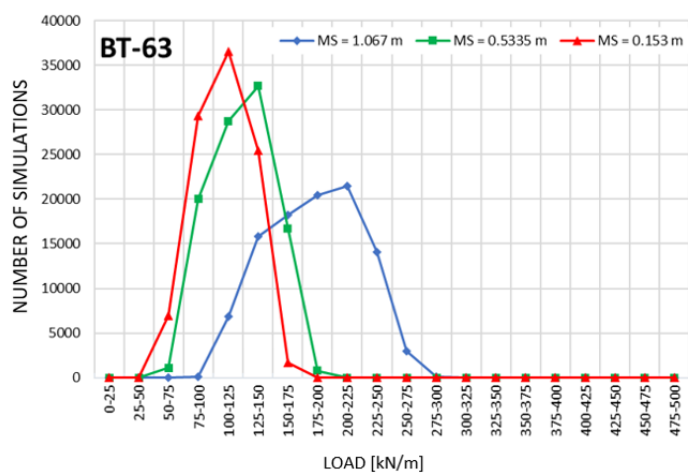

(c) Histogram of the influence of the top flange on the maximum load for beam base BT-63

Figure 15. Beam BT-63 with width variation of the top flange. Source: Oliveira [12]
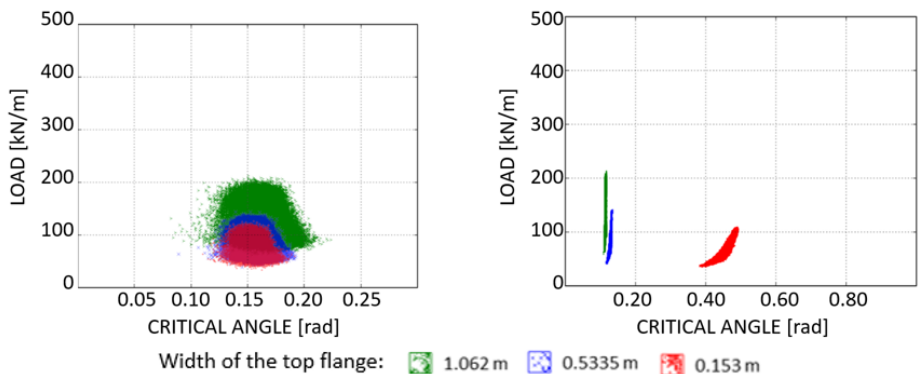

(a) Maximum load of the beam with width variation of the top flange for base BT-72

(b) Load at initial cracking of the beam due to the width of the top flange for beam base BT-72

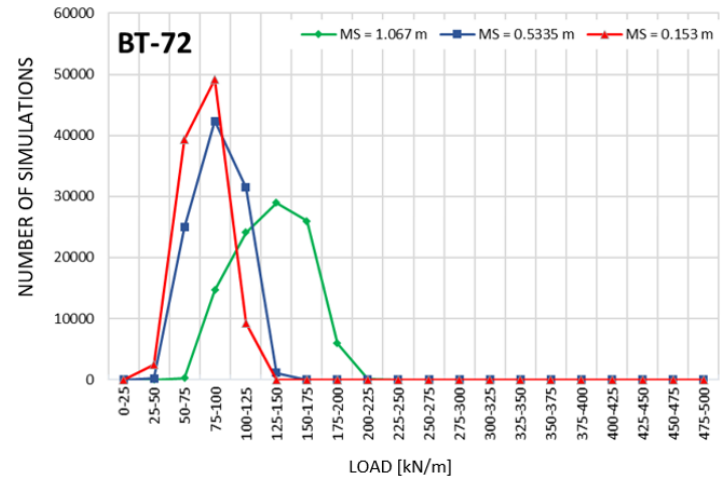

(c) Histogram of the influence of the top flange on the maximum load for beam base BT-72

Figure 16. Beam BT-72 with width variation of the top flange. Source: Oliveira [12] 
Figure 14 presents the results obtained in the simulations using beam BT-54 with the three dimensions of the top flange already described, while Figure 15 presents the results for beam BT-63 and Figure 16 for beam BT-72. Figure 17 shows the comparison between the results obtained for the cross-sections of BT-54, BT-63 and BT-72 with values for the complete top flange.

From the obtained results, the properties from the cross-section were seen to possess factors of extreme importance in the lateral stability of precast beams. When the influence of the top flange (MS) of the beam is analyzed (Figure 13), in a way that modifies its slenderness and moment of lateral inertia, besides the significant reduction in the critical load values, one also notes the distinct influence this has on the state of initial cracking. In this situation, besides the modification of critical load, there was an alteration in the critical angle of initial cracking, which is not significant in the other analyses. In this way, the smaller the dimension of the top flange, the greater is the angle of initial cracking and lower the critical rollover load.

The same occurred when the three distinct cross-sections were analyzed (BT-54, BT-63 and BT-72), and which although the three beams present a similar moment of inertia about the Y-axis, the higher the beam, lower will be the critical load. In addition to the decrease in critical load, the taller beams present an angle for initial cracking lower than the beams with lower heights, although the width of the top flange is the same.

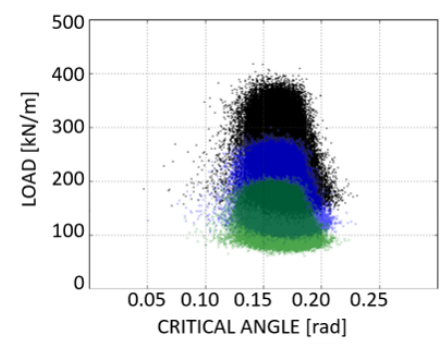

(B)

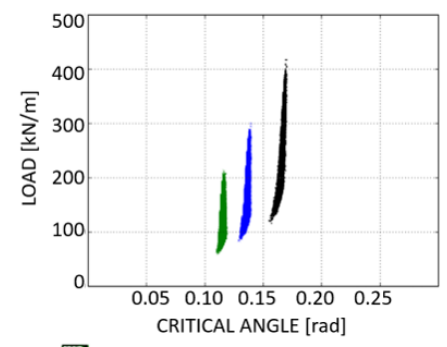

(a) Maximum load of the beams BT-54, BT-63 and BT-72 with $100 \%$ of the top flange width

(b) Load at initial cracking of beams BT-54, BT-63 and BT-72 with $100 \%$ of the top flange width

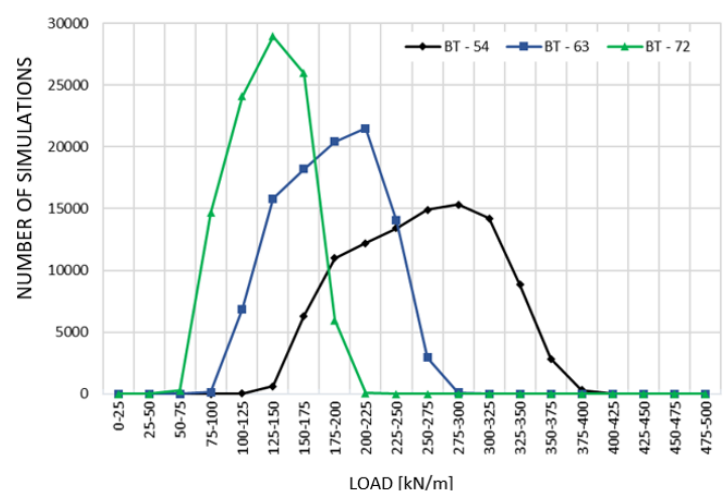

(c) Histogram of the maximum load for beams BT-54, BT-63 and BT-72 with $100 \%$ of the top flange width

Figure 17. Beams BT-54, BT-63 and BT-72 with $100 \%$ of the top flange width. Source: Oliveira [12]

\section{CONCLUSIONS}

Based on the nonlinear analytical solution presented herein, which describes the behavior of a beam with initial eccentricity and rotation on support devices, it was possible to determine the maximum load supported by the beam before rollover. A solution for defining the initial cracking of the beam during the rollover is also presented.

Based on these solutions, a parametric analysis was developed, where the mechanical behavior of the beam was verified under the influence of specific parameters.

From the results obtained from the parametric analysis, the following conclusions were reached:

The increase in the compressive strength of concrete caused an increase in the rollover load in the order of $9 \%$ and $17 \%$ for the values of $75 \mathrm{MPa}$ and $100 \mathrm{MPa}$, respectively, when compared to the values of $50 \mathrm{MPa}$. 
Among the investigated parameters, stiffness to the rotation of the support and the geometry of the cross-section were the factors of foremost influence in the critical rollover load. Therefore, for the situations under analysis, the critical rollover load presents a reduction of:

$42 \%$ to $62 \%$ due to the decrease of the stiffness to the rotation of the support;

$33 \%$ in length reduction of the top flange of $50 \%$ for the reference value, and in $41 \%$ length reduction of the top flange equal to the web width ;

$29 \%$ and $48 \%$ due to the increase in the height of the beam for sections BT-63 and BT-72, respectively, when compared to beam section BT- 54 .

The initial eccentricity and rotation caused significant increases in the critical rollover angle, about $52 \%$ for the initial eccentricity values analyzed (of $\mathrm{L} / 1000$ to $\mathrm{L} / 125$ ) and $47 \%$ for the values of initial rotation (of $0.5^{\circ}$ to $3.0^{\circ}$ ). For the remaining analyzed parameters, the critical rollover angle had a variation of less than $10 \%$.

When there was a decrease in the width of the top flange of the beam ( $50 \%$ of the original), the angle of initial cracking was approximately $15 \%$ higher than the angle obtained for the complete cross-section case. The increase of this angle was higher than $300 \%$ when the length of the top flange possessed the same thickness as the web of the beam.

In the parametric analysis, it was also possible to verify that the initial load at cracking was very close to the critical rollover load of the beam. Nevertheless, the initial cracking angle was maintained close to 0.16 rad for all the analyses, where the cross-section of beam PCI BT-54 has a top flange equal to $1.067 \mathrm{~m}$ in width. However, such angle is sensitive to the variations of the geometric properties of the beam cross-section. As such, it was found that lateral flexural stiffness is the main parameter that governs the cracking of the beam.

However, comparing beams with the same lateral inertia moment, but with differentiated heights, the greater the height, the lower was the angle of initial cracking. This reduction, when compared to beam BT-54, was in the order of $18 \%$ for BT-63 and of $31 \%$ for BT-72.

The conclusion is that for beam PCI BT-54 with a top flange equal to $1.067 \mathrm{~m}$ in width, under the same conditions of support and length, the angle of initial cracking was approximately 0.16 radians, without any direct influence in the analyses from the imperfections of the beam. Noteworthy here is that, in some cases, the critical rollover angle was more significant than the cracking angle. Also, the load for initial cracking is less than the rollover load, highlighting once again that cracking is also unwanted.

In this way, it became evident the importance of safety analyses of precast beams concerning lateral stability during the assembly stage of the structure. The stability of beams is highly dependent on the physical and geometric properties, in what concerns the beam as well as for the support device, where factors of geometric imperfections influence the aspect of safety greatly.

\section{REFERENCES}

[1] R. F. Mast, "Lateral stability of long prestressed concrete beams - Part 2," PCI J., vol. 38, no. 1, pp. 70-88, Jan-Feb 1993.

[2] M. C. V. D. Lima, “Contribuição ao estudo da instabilidade lateral de vigas pré-moldadas,” Ph.D. dissertation, Esc. Eng. São Carlos, Univ. São Paulo, 2002.

[3] R. Tremblay and D. Mitchell, "Collapse during construction of a precast girder bridge," J. Perform. Constr. Facil., vol. 20, no. 2, pp. $113-125,2006$.

[4] R. G. Oesterle et al., Investigation of Red Mountain Freeway Bridge Girder Colapse (CTL Group Project 262291). Skokie, IL, USA: Bridge Group, Arizona Dept. Transp., Nov 2007, pp. 67.

[5] J. M. Bairán and A. Cladera, "Collapse of a precast concrete beam for a light roof. Importance of elastomeric bearing pads in the element's stability," Eng. Fail. Anal., vol. 39, pp. 188-199, Apr 2014.

[6] C. J. Burgoyne and T. J. Stratford, "Lateral instability of long-span prestressed concrete beams on flexible bearings," Struct. Eng., vol. 79, no. 6, pp. 23-26, Mar 2001.

[7] R. H. Plaut and C. D. Moen, "Stability of unbraced concrete beams on bearing pads including wind loading," J. Struct. Eng., vol. 69, pp. 246-254, Jun 2014.

[8] J. H. Lee, I. Kalkan, J.-J. Lee, and J.-H. Cheung, "Rollover instability of precast girders subjected to wind load," Mag. Concr. Res., vol. 69 , no. 2 , pp. 68-83, 2017.

[9] J. H. Lee, "Evaluation of the lateral stability of precast beams on an elastic bearing support with a consideration of the initial sweep," Eng. Struct., vol. 143, no. 1, pp. 101-112, 2017.

[10] P. A. Krahl, R. Carrazedo, and M. K. El Debs, "Analytical solutions for rollover instability of concrete beams on elastomeric bearing pads," Eng. Struct., vol. 174, pp. 154-164, 2018. 
[11] J. B. Hurff and L. F. Kahn, "Rollover stability of precast, prestressed concrete bridge girders with flexible bearings," PCI J., vol. 57, no. 4, pp. 96-107, 2012.

[12] M. F. A. Oliveira, "Estudo analítico do tombamento de vigas pré-moldadas sobre almofadas de apoio,” M.S. thesis, Prog. Pós-grad. Eng. Civ., Univ. Fed. Uberlândia, Uberlândia, 2019.

[13] P. A. Krahl, M. F. A. Oliveira, G. H. Siqueira, and M. C. V. Lima, "Analytical nonlinear rollover behavior of cambered precast concrete beams on flexible supports," J. Struct. Eng., vol. 146, no. 2, pp. $04019200,2020$.

[14] R. V. Southwell, "On the analysis of experimental observations in problems of elastic stability," Proc. R. Soc. Lond., vol. 135, pp. 601-616, 1932.

[15] Associação Brasileira de Normas Técnicas, Projeto de Estruturas de Concreto - Procedimento, ABNT NBR 6118:2014, 2014.

[16] G. R. Consolazio and H. R. Hamilton, Lateral Bracing of Long-Span Florida Bulb-Tee Girders. Florida: Univ. Florida, Depart. Civ. Coast. Eng., 2007, pp. 91.

[17] Joint Committee on Structural Safety, Probabilistic Model Code Part 3 - Resistance Models, Concrete Properties, 2000.

[18] N. Yazdani, S. Eddy, and C. S. Cai, "Effect of bearing pads on precast prestressed concrete bridges," J. Bridge Eng., vol. 5, no. 3, pp. 224-232, 2000.

[19] Associação Brasileira de Normas Técnicas, Projeto e Execução de Estruturas de Concreto Pré-moldado, ABNT NBR 9062:2001, 2001.

[20] Associação Brasileira de Normas Técnicas, Aparelhos de Apoio de Elastômero Fretado - Especificação e Métodos de Ensaio, ABNT NBR 19783:2015, 2015.

[21] M. T. S. A. Cardoso, "Instabilidade lateral de vigas pré-moldadas sobre apoios elastoméricos considerando o efeito das imperfeições geométricas,” M.S. thesis, Prog. Pós-grad. Eng. Civil, Univ. Fed. Uberlândia, Uberlândia, 2017.

Author contributions: MFAO: data acquisition, methodology, numerical and analytical analysis, writing; PAK: conceptualization, methodology, formal analysis, writing, supervision; MCVL: conceptualization, formal analysis, writing, supervision.

Editors: Vladimir Guilherme Haach, José Luiz Antunes de Oliveira e Sousa, Guilherme Aris Parsekian. 